\title{
Rostrocaudal Dynamics of CSF Biomarkers
}

\author{
Andrew Tarnaris $\cdot$ Ahmed K. Toma \\ Miles D. Chapman • Axel Petzold • Geoff Keir • \\ Neil D. Kitchen $\cdot$ Laurence D. Watkins
}

Accepted: 15 December 2010/Published online: 30 December 2010

(C) Springer Science+Business Media, LLC 2010

\begin{abstract}
The rostrocaudal gradient (RCG) of markers present in cerebrospinal fluid (CSF) has not been studied adequately due to lack of appropriate control populations and ethical restrictions. The aim of this study is to understand the rostrocaudal gradient of CSF biomarkers. We contacted a study comparing CSF levels of seven biomarkers from cisternal (rostral) and lumbar (caudal) CSF obtained from patients with trigeminal neuralgia and tension-type headache. The RCGs of CSF/serum albumin ratio, 8-isoprostane. GFAP, total tau and beta amyloid protein were higher than one. The RCGs of lactate, VEGF and the heavy chain of neurofilament protein were lower than one. The study provides new values for several commonly examined markers of cisternal CSF. Knowledge of the RCG gradient of different CSF markers is important in interpreting studies reporting ventricular CSF values.
\end{abstract}

Keywords Rostrocaudal gradient - CSF - Biomarkers . Cisternal

A. Tarnaris $(\bowtie) \cdot$ A. K. Toma · N. D. Kitchen · L. D. Watkins The Victor Horsley Department of Neurosurgery, National Hospital for Neurology and Neurosurgery, Box 32, Queen Square, London, WC 1N 3BG, UK e-mail: andrewtarnaris@gmail.com

M. D. Chapman · A. Petzold · G. Keir

Department of Neuroimmunology, Institute of Neurology, Queen Square, London, WC 1N 3BG, UK

\section{A. Petzold}

Department of Neurology, Free University Amsterdam, Amsterdam, The Netherlands

\section{Introduction}

The dynamics of cerebrospinal fluid (CSF) markers along the craniospinal axis has not been adequately studied due to restricted access to ventricular CSF samples [1-3]. Many brain-specific proteins are produced by the brain parenchyma and then are transported across the ependyma into the CSF spaces. The large majority of them are derived from serum, whereas others are produced exclusively by the brain parenchyma. The movement of molecules across the blood-brain barrier (BBB) and the blood-CSF barrier depends on concentration gradients and flow [4]. The particular dynamics of brain-derived proteins depend on their sources which are either brain cells (neurons, glial cells) or leptomeningeal cells [5]. From there, following the bulk flow, a portion flows down the spinal axis to the lumbar thecal sac where reabsorption as well as secretion occurs.

Access to lumbar CSF provides us with diagnostic information about different neurological conditions [6]. Levels of markers in CSF may be studied and conclusions about the pathophysiological mechanisms underlying each condition may be extrapolated [7]. However, the caudal protein concentration from the lumbar thecal sac does not accurately reflect the rostral concentrations from the cisternal or ventricular CSF. Hence a combined knowledge of both rostral and caudal concentration is needed for a complete interpretation of the pathological significance of each biomarker. Sampling of higher levels along the craniospinal axis may not be ethically feasible hence limiting the yield of diagnostic information from lumbar CSF only.

The aim of the study is to study the gradient of markers along the craniospinal axis in a normal population. We also provide cisternal values for markers who have not studied previously in a normal population. 


\section{Experimental Procedure}

Cisternal CSF was collected from 6 patients suffering from trigeminal neuralgia (TGN). All patients had idiopathic TGN, other neurological causes having been excluded with appropriate imaging. The patients have signed a consent form to participate in the study. The study received ethical approval from the Local Research Ethics Committee (Great Ormond Street Hospital L.R.E.C.). Lumbar CSF was also collected from 6 patients investigated for tension-type headache and acted as a control group for lumbar samples (LC). $5 \mathrm{mls}$ of CSF was removed during lumbar puncture. No pathology was found during routine investigations with blood tests and imaging (MRI) for this group. The cisternal CSF sample in patients with TGN was obtained following durotomy during a microvascular decompression. All patients were fasted at the time of sampling. Care was taken to remove all blood by suction prior to opening the dura, to ensure the sample was not contaminated. Red cell and white cell counts were performed as per routine sample analysis prior to centrifugation. All samples were centrifuged within 20 min following collection and the supernatant aliquoted to $1 \mathrm{ml}$ polypropelene tubes, frozen and stored at $-80^{\circ} \mathrm{C}$ until analysis.

CSF albumin was measured using an in-house immunoturbidimetric assay; $5 \mu \mathrm{l}$ of sample was mixed in an ELISA plate well (Nunc) with $250 \mu \mathrm{l}$ of anti-human albumin (DiaSorin), diluted $1 / 16$ in $0.9 \%$ saline, and allowed to stand for ten minutes before being read at $350 \mathrm{~nm}$. The assay was blanked with saline, calibrated on a $0.5 \mathrm{~g} / \mathrm{l}$ standard and calculated using the formula: Albumin $=([\mathrm{OD}$ test $-\mathrm{OD}$ blank $) /(\mathrm{OD}$ standard $-\mathrm{OD}$ blank]) $\times 1.0 \mathrm{~g} / \mathrm{l}$. Any samples above $0.5 \mathrm{~g} / \mathrm{l}$ were diluted in saline and re-assayed. CSF lactate was analyzed enzymatically on an YSI 2700 STAT PLUS analyzer (YSI, USA) according to manufacturer's instructions. VEGF was assayed using a commercial assay (Amersham Biotrak $^{\mathrm{TM}}$ human VEGF ELISA, GE Healthcare, U.K.). 8-isoprostane was calculated using a commercial kit (8-Isoprostane EIA kit, Cayman Chemical Company, MI, US). Heavy chain of the neurofilament protein $\left(\mathrm{NfH}^{\mathrm{SMI} 35}\right)$ was assayed by a technique described previously [8]. The technique for the quantification of GFAP (GFAP ${ }^{\text {SMI26 }}$ ) has also been described previously [9]. $\mathrm{A} \beta_{1-42}$ was measured using a commercial kit (Innotest ${ }^{\circledR} \beta$-amyloid $(1-42)$, Innogenetics, Belgium). The total tau was measured by a commercial kit Innotest $^{\circledR}$ hTAU Ag, Innogenetics, Belgium). The markers chosen were studied as part of a different published study in patients with idiopathic normal pressure hydrocephalus [10]. For NfH \& GFAP lumbar CSF levels reference values [11] from a larger study with 33 samples were used. For total tau and $\mathrm{A} \beta$
1-42 lumbar CSF levels reference values [12] from a larger study with 100 samples were used.

The median values and range of the examined markers will be presented. The Mann-Whitney non-parametric test was used to test for significant differences between the CC and LC levels. Where reference values were used statistics were not calculated.

The Spearman's correlation test was used to test for significant correlations between age, the Qalb and the other markers both in cisternal and lumbar levels. The level of significance was set at 0.05 .

\section{Results}

The mean age of the 6 TGN patients was $56.5( \pm 9.3)$ years (range: 52-76). The mean age of the 6 patients investigated for headache was $50.5( \pm 10.6)$ years (range: 35-62). The difference in age of the two control groups was not statistically significant (Mann-Whitney $U$ test, $P=0.234)$. The mean red cell count $(\mathrm{RCC})$ in the cisternal CSF prior to centrifugation was $2.66( \pm 3.88)$ and the mean white cell count (WCC) $0.33( \pm 0 / 51)$. The mean RCC in the lumbar CSF prior to centrifugation was $9.66( \pm 19.8)$, and the WCC $0.16( \pm 0.4)$. There were no significant differences in the RCC and WCC of the cisternal and lumbar CSF.

\section{Differences Between Levels of Markers}

No significant differences were found between the cisternal and the lumbar levels of the examined markers.

\section{Rostrocaudal Gradients of Markers}

These are presented in Table 1. RCG higher than one means that the concentration is higher in the cisternal CSF when compared to the lumbar CSF. The RCG of GFAP cannot be calculated since the median value is 0 , however it is assumed that it has to be higher than one since the cisternal median is $0.2 \mathrm{pg} / \mathrm{ml}$. The RCG of CSF/serum albumin ratio, 8-isoprostane. GFAP and total tau and beta amyloid protein was higher than one. The RCG of lactate, VEGF and the heavy chain of neurofilament protein was lower than one.

\section{Correlation of Examined Markers with Qalb}

All markers appear independent from Qalb, except the cisternal levels of $\mathrm{A} \beta_{1-42}$ which exhibit a significant positive correlation with Qalb $(R=0.886, P=0.019)$. 
Table 1 Presentation of age, sex and the levels of the different markers examined

\begin{tabular}{|c|c|c|c|c|c|}
\hline & $\begin{array}{l}\text { Cisternal control } \\
\operatorname{CSF}(n=6)\end{array}$ & $\begin{array}{l}\text { Lumbar control } \\
\operatorname{CSF}(n=6)\end{array}$ & $\begin{array}{l}\text { Statistical } \\
\text { significance }\end{array}$ & $\begin{array}{l}\text { Rostrocau-dal } \\
\text { gradient }\end{array}$ & $\begin{array}{l}\text { Correlation } \\
\text { with Qalb }\end{array}$ \\
\hline Age (years) & $56.5(52-76)$ & $50.5(35-62)$ & n.s & & \\
\hline Sex (Male: Female) & $4: 2$ & $2: 4$ & N/A & & \\
\hline Qalb & $0.003(0-2.41)$ & $0.0017(0.0002-0.0064)$ & n.s & 1.7 & - \\
\hline Lactate & $1.71(1.01-2.93)$ & $2.07(1.54-4.26)$ & n.s & 0.82 & n.s \\
\hline VEGF & $6.27(0-24.6)$ & 20.19 (17.8-23.9) & n.s & 0.31 & n.s \\
\hline 8-isoprostane & $40.23(38.12-45.06)$ & $37.81(36.28-43.07)$ & n.s & 1.06 & n.s \\
\hline GFAP ${ }^{\text {SMI26 }}$ & $0.2(0.13-1.31)$ & $0(0-60)^{\mathrm{a}}$ & N/A & - & n.s \\
\hline $\mathrm{NfH}^{\mathrm{SMI} 35}$ & $0.01(0-1.34)$ & $0.18(0.07-0.30)^{\mathrm{a}}$ & N/A & 0.05 & n.s \\
\hline Total tau & $285(54.5-1158)$ & $195(121-294)^{\mathrm{b}}$ & N/A & 1.46 & n.s \\
\hline $\mathrm{A} \beta_{1-42}$ & $930(113-1458)$ & $849(682-1063)^{\mathrm{b}}$ & N/A & 1.09 & $R=0.886(0=0.019)$ \\
\hline
\end{tabular}

Spearman's correlations are presented. Mann-Whitney test was used to test for statistical significance

The values presented are the median with the range in brackets. Reference values used from ${ }^{\mathrm{a}}[11]$ and ${ }^{\mathrm{b}}$ [12]

\section{Correlations Between Patient's Age and Markers}

Only VEGF levels demonstrated a positive trend with age in patients with TGN $(R=0.771, P=0.072)$. All other markers did not show any correlation with age.

\section{Discussion}

The dynamics of brain-derived proteins have been explained by Reiber [4, 5, 13, 14]. He suggested that the CSF flow rate, and not the blood-CSF barrier dysfunction as previously thought is the most important determinant for understanding the pathological changes of both blood and brain-derived proteins in CSF. In order to characterise the dynamics he analysed the concentration gradients of CSF/ serum albumin ratio $\left(\mathrm{Q}_{\mathrm{alb}}\right)$ and the ventricular/lumbar CSF concentration gradient. Pathologically decreased CSF flow rate was characterised by increased $\mathrm{CSF} /$ serum albumin ratio $\left(\mathrm{Q}_{\mathrm{alb}}\right)$. According to his theory therefore: (1) Brainderived proteins show a decrease in concentration between ventricular and lumbar CSF (i.e. RCG > 1) in normal situations. Their concentration does not vary with pathologically decreasing CSF flow rate (i.e. in cases of a bloodCSF barrier dysfunction) and therefore it is independent of the $\mathrm{Q}_{\mathrm{alb}}$. (2) In the case of CSF proteins from leptomeningeal cells an increasing concentration between normal ventricular and lumbar CSF is observed (similar to bloodderived proteins) (i.e. $\mathrm{RCG}<1$ ). In the case of pathologically decreasing CSF flow rate a linearly increasing concentration in CSF is observed, that therefore being dependent on $\mathrm{Q}_{\mathrm{alb}}$. (3) Group with a non-negligible bloodderived fractions in addition to brain-derived fractions. In this group it is important to decide whether a quotient or an absolute concentration of the brain-derived protein is preferred as the most sensitive evaluation with reference to the albumin quotient.

The age of patients does not appear to influence the levels of markers; similar findings have been shown by other studies using the same ELISA [8]. We found a positive trend (but not a significant correlation) between the age of patients with TGN and $\mathrm{A} \beta$ 1-42 levels; similar findings with normal groups have been reported $[15,16]$. Other studies however have found a correlation of lactate levels with age in opposition to our findings [17]. Due to the inclusion of a narrow age range and the small number of the subjects the current data cannot exclude correlations of markers with age.

Under normal circumstances lactate clearance from CSF is slowly taken up by the brain via diffusion [18] and by the arachnoid villi by bulk flow [19] then partially metabolised to pyruvate. The rostrocaudal gradient (RCG) of lactate was 0.82 . We verified the earlier studies of Posner and Plum who found almost equal CSF lactate levels between the cisterns and lumbar thecal sac, and that of Vamosi et al. who, similarly to us, found higher lumbar lactate levels when compared to cisternal levels [20, 21].

The RCG of 8-isoprostane was 1.06. It appears therefore that 8-isoprostane is secreted and absorbed in an almost equal rate across the craniospinal axis in control subjects.

The RCG for VEGF is 0.31. In the case of VEGF the ventricular levels were independent of Qalb (Spearman's correlation, $R=-0.32, P=0.144)$. VEGF has both a brain and blood-derived fraction. A limitation of our study was that due to ethical restrictions we did not have access to serum samples and therefore it is impossible to calculate the blood-derived fraction of the ventricular VEGF levels.

GFAP is also a brain-derived protein. The RCG in normal subjects cannot be calculated since the median value for a control population is 0 (with a range of $0-60$ ). 
Although one will assume that the gradient is $>1$ since the cisternal median GFAP value is $0.2 \mathrm{pg} / \mathrm{ml}$. The gradient agrees with the model for brain-derived proteins described by Reiber. The levels of NfH did not correlate with age in any of the groups tested, agreeing with previous reports [22]. The lumbar levels of $\mathrm{NfH}$ were almost 18 times higher than the cisternal levels. According to Reiber's theory an active secretion of the protein should occur by the leptomeninges along the craniospinal axis; such findings have been demonstrated in cultured human cells in vitro [23]. The levels appear independent of $\mathrm{Q}_{\mathrm{alb}}$.

The cisternal levels of total tau were almost 1.5 times higher in the control group when compared to the lumbar levels. The levels were independent of Qalb consistent with Reiber's theory about the CSF dynamics of brain-derived proteins. The RCG of A $\beta 1-42$ is 1.09 in control subjects, respectively. The A $\beta_{1-42}$ levels are dependent on the $\mathrm{Q}_{\mathrm{alb}}$ ( $R=0.886, P=0.019$ ) in the control subjects. Increases in $\mathrm{A} \beta$ levels due to decreasing CSF clearance and hence dependence in Qalb has been demonstrated in experimental models of chronic hydrocephalus [24]. The dynamics of A $\beta 1-42$ suggest according to Reiber's theory that $\mathrm{A} \beta 1-42$ is secreted by the leptomeningeal cells along the craniospinal axis. It has been indeed shown that there is amyloid accumulation in the cortical leptomeninges of both aged individuals and patients with $\operatorname{AD}[25,26]$. The potential of amyloid deposition in the spinal cord has been demonstrated in vivo with MR imaging in cases of amyloidosis and spinal vascular malformations [27, 28]. Authors of a study where the fluctuation of $\mathrm{A} \beta$ 1-42 levels were studied assumed that there was no RCG in normal subjects [29]. However, they did not sample ventricular CSF but instead collected 25-35 mls of lumbar CSF. Our study found a small positive gradient (1.09). However, it has been shown the volume of spinal CSF is a mean of $81 \pm 13 \mathrm{ml}$ in normal individuals [30] rendering the above method of calculating a RCG methodologically incorrect.

There are several limitations due to ethical restrictions. We were therefore unable to measure the markers in serum samples and hence calculate the blood-derived fraction of some markers. Rostral and caudal values were also obtained from different sets of subjects, however a lumbar puncture in patients with TGN was not permitted for ethical reasons, since the procedure is not part of the routine diagnostic protocol. Although there may be an argument against patients with TGN having non-pathological CSF composition, there are no published studies in the literature to reflect changes with regards to the markers studied. For logistical reasons the samples were not obtained at the same time of the day. Hence a bias may have been introduced with regards to diurnal and seasonal rhythms, and their effect on the levels of the markers. Effects that are difficult to standardise such as the height of subjects may effect the concentration of markers in lumbar CSF [31]. Intra-individual variations however may remain stable over a short period [32]. Sampling cisternal CSF from patients with TGN cannot exclude concomitant pathologies that may affect the levels of the markers, however at the time of surgery other pathologies were not known, and imaging of the patients had excluded underlying pathologies. Last, inter-laboratory variations in ELISA results reporting cannot be excluded where reference values from larger studies are used in the lumbar samples; however this is balanced by the increased certainty of the reference values the larger studies provide.

\section{Conclusions}

Due to the small clinical sample our data may not provide reference values but may act as a starting point to provide a further insight into the dynamics of several CSF markers in a normal population, providing at the same time values of cisternal CSF for several CSF markers never studied before. Knowledge of the gradient of different CSF markers is important in interpreting studies reporting ventricular CSF values.

Acknowledgments AT and AKT were supported by a grant from B Braun/Aesculap Academia.

Conflict of interests There are no conflict of interests.

Ethical approval The study received ethical approval from the Local Research Ethics Committee (Great Ormond Street Hospital L.R.E.C.) (06/Q0505/59).

\section{References}

1. Grove J, Schechter PJ, Hanke NF, de Smet Y, Agid Y, Tell G et al (1982) Concentration gradients of free and total gammaaminobutyric acid and homocarnosine in human CSF: comparison of suboccipital and lumbar sampling. J Neurochem 39(6): $1618-1622$

2. Menachem EB, Persson L, Schechter PJ, Haegele KD, Huebert N, Hardenberg J (1989) Cerebrospinal fluid parameters in healthy volunteers during serial lumbar punctures. J Neurochem 52: 632-635

3. Sommer JB, Gaul C, Heckmann J, Neundorfer B, Erbguth FJ (2002) Does lumbar cerebrospinal fluid reflect ventricular cerebrospinal fluid? A prospective study in patients with external ventricular drainage. Eur Neurol 47(4):224-232

4. Reiber H (1994) Flow rate of cerebrospinal fluid (CSF)-a concept common to normal blood-CSF barrier function and to dysfunction in neurological diseases. J Neurol Sci 122(2):189-203

5. Reiber H (2003) Proteins in cerebrospinal fluid and blood: barriers, CSF flow rate and source-related dynamics. Restor Neurol Neurosci 21(3):79-96

6. Hühmer AF, Biringer RG, Amato $\mathrm{H}$, Fonteh $\mathrm{AN}$, Harrington MG (2006) Protein analysis in human cerebrospinal fluid: 
Physiological aspects, current progress and future challenges. Dis Markers 22(1):3-26

7. Reiber H (1998) Cerebrospinal fluid-physiology, analysis and interpretation of protein patterns for diagnosis of neurological diseases. Mult Scler 4(3):99-107

8. Petzold A, Keir G, Green AJE, Giovannoni G, Thompson EJ (2003) A specific ELISA for measuring neurofilament heavy chain phosphoforms. J Immunol Methods 278(1-2):179-190

9. Petzold A, Keir G, Green AJE, Giovannoni G, Thompson EJ (2004) An ELISA for glial fibrillary acidic protein. J Immunol Methods 287(1-2):169-177

10. Tarnaris A, Toma AK, Chapman MD, Petzold A, Kitchen ND, Keir G et al (2009) The longitudinal profile of CSF markers during external lumbar drainage. Br Med J 80(10):1130

11. Petzold A, Brettschneider J, Jin K, Keir G, Murray NM, Hirsch NP et al (2009) CSF protein biomarkers for proximal axonal damage improve prognostic accuracy in the acute phase of Guillain-Barré syndrome. Muscle Nerve 40(1):42-49

12. Hulstaert F, Blennow K, Ivanoiu A, Schoonderwaldt HC, Riemenschneider M, Deyn PPD et al (1999) Improved discrimination of AD patients using B-amyloid (1-42) and tau levels in CSF. Neurology 52(8):1555

13. Reiber H (2001) Dynamics of brain-derived proteins in cerebrospinal fluid. Clinica Chimica Acta 310(2):173-186

14. Reiber H, Peter JB (2001) Cerebrospinal fluid analysis: diseaserelated data patterns and evaluation programs. J Neurol Sci 184(2):101-122

15. Van Gool WA, Schenk DB, Bolhuis PA (1994) Concentrations of amyloid-beta protein in cerebrospinal fluid increase with age in patients free from neurodegenerative disease. Neurosci Lett 172(1-2): 122

16. Kanai M, Matsubara E, Isoe K, Urakami K, Nakashima K, Arai H et al (1998) Longitudinal study of cerebrospinal fluid levels of tau, A beta ${ }_{1-40}$, and A beta1-42 (43) in Alzheimer's disease: a study in Japan. Ann Neurol 44(1):17

17. Pryce JD, Gant PW, Saul KJ (1970) Normal concentrations of lactate, glucose, and protein in cerebrospinal fluid, and the diagnostic implications of abnormal concentrations. Clin Chem 16(7):562

18. Prockop LD (1968) Cerebrospinal fluid lactic acid. Clearance and effect on facilitated diffusion of a glucose analogue. Neurology 18(2): 189

19. Valenca LM, Shannon DC, Kazemi H (1971) Clearance of lactate from the cerebrospinal fluid. Neurology 21(6):615-620

20. Vámosi B, Diószeghy P, Molnar L (1983) Lactate and pyruvate content of the human cisternal cerebrospinal fluid. Normal values, age and sex dependency, correlations with glucose concentrations. Archiv für Psychiatrie und Nervenkrankheiten 232(6):521

21. Posner JB, Plum F (1967) Independence of blood and cerebrospinal fluid lactate. Arch Neurol 16(5):492

22. Brettschneider J, Petzold A, Schottle D, Claus A, Riepe M, Tumani $\mathrm{H}$ (2006) The neurofilament heavy chain $(\mathrm{NfH})$ in the cerebrospinal fluid diagnosis of Alzheimer's disease. Dement Geriatr Cogn Disord 21(5-6):291-295

23. DeGiorgio LA, Sheu KF, Blass JP (1994) Culture from human leptomeninges of cells containing neurofilament protein and neuron-specific enolase. J Neurol Sci 124(2):141

24. Silverberg G, Caralopoulos I, Saul T, Slone S, Miller M, Messier A et al (2009) Amyloid and tau accumulation precede CSF production decline in normal aging. Cerebrospinal Fluid Res 6(Suppl 1):S38

25. Hamano T, Yoshimura M, Yamazaki T, Shinkai Y, Yanagisawa K, Kuriyama M et al (1997) Amyloid [beta]-protein (A [beta]) Accumulation in the Leptomeninges during Aging and in Alzheimer Disease. J Neuropathol Exp Neurol 56(8):922

26. Shinkai $Y$, Yoshimura $M$, Morishima-Kawashima M, Ito $Y$, Shimada H, Yanagisawa K et al (1997) Amyloid -protein deposition in the leptomeninges and cerebral cortex. Ann Neurol 42(6):899-908

27. Hart MN, Merz P, Bennett-Gray J, Menezes AH, Goeken JA, Schelper RL et al (1988) beta-amyloid protein of Alzheimer's disease is found in cerebral and spinal cord vascular malformations. Am J Pathol 132(1):167

28. Horowitz S, Thomas C, Gruener G, Nand S, Shea JF (1998) MR of leptomeningeal spinal and posterior fossa amyloid. AJNR Am J Neuroradiol 19(5):900

29. Bateman RJ, Wen G, Morris JC, Holtzman DM (2007) Fluctuations of CSF amyloid-ss levels: implications for a diagnostic and therapeutic biomarker. Neurology 68(9):666

30. Edsbagge M, Starck G, Zetterberg H, Ziegelitz D, Wikkelso C (2009) Volumes of spinal CSF and the spinal cord. Hydrocephalus 16-19, Sept 2009, Baltimore US2009

31. Hartikainen P, Soininen H, Reinikainen KJ, Sirviö J, Soikkeli R, Riekkinen PJ (1991) Neurotransmitter markers in the cerebrospinal fluid of normal subjects effects of aging and other confounding factors. J Neural Transm 84(1):103-117

32. Hildebrand J, Moussa Z, Raftopoulos C, Vanhouche J, Laute MA, Przedborski S (1992) Variations of homovanillic acid levels in ventricular cerebrospinal fluid. Acta Neurol Scand 85(5):340-342 